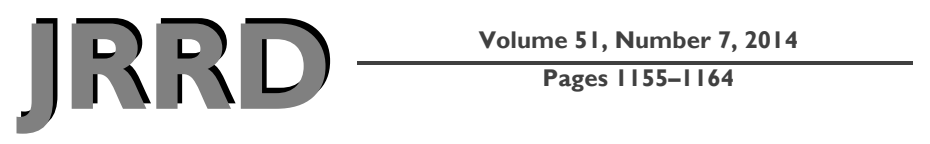

\title{
Validity and reliability of rectus femoris ultrasound measurements: Comparison of curved-array and linear-array transducers
}

\author{
Kendra Hammond, MD; ${ }^{1-2}$ Jobby Mampilly, MD; ${ }^{1-2}$ Franco A. Laghi, BS; ${ }^{1}$ Amit Goyal, MD; ${ }^{1-2}$ Eileen G. \\ Collins, RN, PhD; ${ }^{1-3}$ Conor McBurney, BS; ${ }^{1}$ Amal Jubran, MD; ${ }^{1-2^{*}}$ Martin J. Tobin, MD $^{1-2}$ \\ ${ }^{1}$ Edward Hines, Jr. Department of Veterans Affairs Hospital, Hines, IL; ${ }^{2}$ Division of Pulmonary and Critical Care \\ Medicine, Loyola University Stritch School of Medicine, Maywood, IL; ${ }^{3}$ Department of Biobehavioral Health Science, \\ University of Illinois at Chicago College of Nursing, Chicago, IL
}

\begin{abstract}
Muscle-mass loss augers increased morbidity and mortality in critically ill patients. Muscle-mass loss can be assessed by wide linear-array ultrasound transducers connected to cumbersome, expensive console units. Whether cheaper, handcarried units equipped with curved-array transducers can be used as alternatives is unknown. Accordingly, our primary aim was to investigate in 15 nondisabled subjects the validity of measurements of rectus femoris cross-sectional area by using a curvedarray transducer against a linear-array transducer - the referencestandard technique. In these subjects, we also determined the reliability of measurements obtained by a novice operator versus measurements obtained by an experienced operator. Lastly, the relationship between quadriceps strength and rectus area recorded by two experienced operators with a curved-array transducer was assessed in 17 patients with chronic obstructive pulmonary disease (COPD). In nondisabled subjects, the rectus cross-sectional area measured with the curved-array transducer by the novice and experienced operators was valid (intraclass correlation coefficient [ICC]: 0.98, typical percentage error [\%TE]: 3.7\%) and reliable (ICC: 0.79, \%TE: 9.7\%). In the subjects with COPD, both reliability (ICC: 0.99 ) and repeatability (\%TE: 7.6\% and 9.8\%) were high. Rectus area was related to quadriceps strength in COPD for both experienced operators (coefficient of determination: 0.67 and 0.70 ). In conclusion, measurements of rectus femoris crosssectional area recorded with a curved-array transducer connected to a hand-carried unit are valid, reliable, and reproducible, leading us to contend that this technique is suitable for cross-sectional and longitudinal studies.
\end{abstract}

Key words: COPD, critical illness myopathy, critical illness neuropathy, human muscle, intensive care unit, probe configuration, quadriceps femoris, reproducibility, sarcopenia, ultrasound imaging.

\section{INTRODUCTION}

Loss of muscle mass is common in critically ill patients [1-5] and is linked to morbidity and mortality [6]. Magnetic resonance and computed tomography are reference-standard imaging techniques for detecting decreases in muscle mass [7-10]. The high expense and cumbersome nature of these techniques has stimulated interest in ultrasonography [5,9,11-12]. Ultrasonography is valid and reliable and has excellent repeatability [9,11,13], making it ideal for assessing longitudinal changes in muscle dimensions, particularly of locomotor muscles [14].

To include a field wide enough to capture the crosssectional image of locomotor muscles, investigators employ wide linear-array transducers connected to bulky and expensive console ultrasound units [9,12,15] (Figure 1). Hand-carried units, by contrast, are portable and 3-4 times less expensive than console units. Hand-carried ultrasounds, however, can usually be equipped only with linear-array transducers that are often too narrow to capture

\footnotetext{
Abbreviations: $\mathrm{BMI}=$ body mass index, $\mathrm{COPD}=$ chronic obstructive pulmonary disease, $\mathrm{MVC}=$ maximum voluntary contraction, $\mathrm{SE}=$ standard error.

*Address all correspondence to Amal Jubran, MD; Division of Pulmonary and Critical Care Medicine, Edward Hines, Jr. VA Hospital (111N), 5th Ave and Roosevelt Rd, Hines, IL 60141; 708-202-2705; fax: 708-202-7907.

Email: ajubran@lumc.edu

http://dx.doi.org/10.1682/JRRD.2013.08.0187
} 

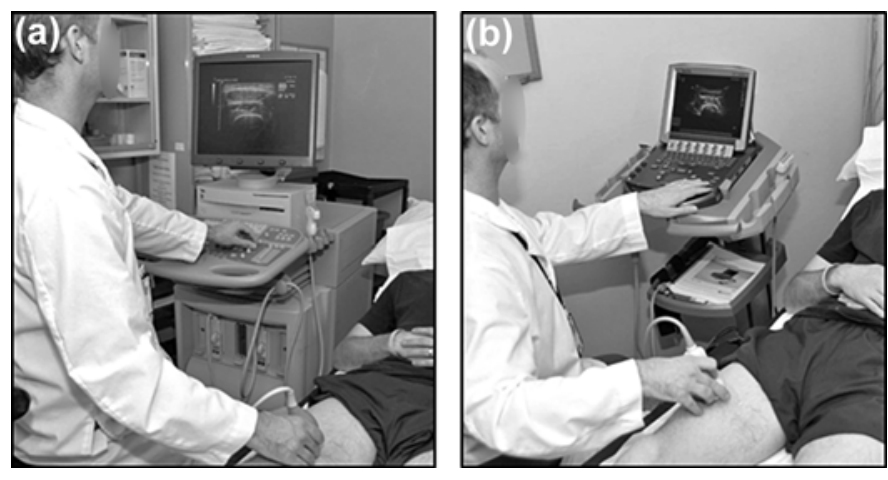

Figure 1.

(a) Console and (b) hand-carried ultrasound units. Hand-carried units are portable and 3-4 times less expensive than console units. Both can be equipped with curved-array transducer that can capture entire cross-sectional image of large locomotor muscles.

the entire cross-sectional image of lower-limb muscles. These units can also be equipped with curved-array transducers, which capture larger and deeper images than those obtained with linear-array transducers [15]. Whether locomotor-muscle measurements obtained with curved-array and linear-array transducers are equivalent remains unknown [15-16]. Accordingly, our primary objective was to assess intertransducer validity of rectus femoris measurements obtained using a curved-array transducer connected to a hand-carried unit against measurements obtained with a linear-array transducer-the referencestandard technique. We also tested three secondary objectives. The first was to determine interoperator agreement or reliability of measurements obtained by novice and experienced operators in nondisabled subjects. The second was to determine the reliability and repeatability of measurements obtained by two experienced operators in patients with chronic obstructive pulmonary disease (COPD). Finally, the third was to determine the structure-function relationship of the muscle by exploring the relationship between quadriceps strength and the cross-sectional area of the rectus femoris recorded by two experienced operators with a curved-array transducer [9].

\section{METHODS}

\section{Subjects}

Fifteen nondisabled subjects (two women) and seventeen ambulatory men with COPD (mean \pm standard error [SE] forced expiratory volume in $1 \mathrm{~s}=45 \% \pm 3 \%$ predicted) volunteered for the study. Age of the nondisabled subjects ranged from 21 to $42 \mathrm{yr}$ (mean $=30 \mathrm{yr}$ ) and body mass index (BMI) ranged from 22 to $31 \mathrm{~kg} / \mathrm{m}^{2}$ (mean $\left.=27 \mathrm{~kg} / \mathrm{m}^{2}\right)$. Age of the subjects with COPD ranged from 55 to $82 \mathrm{yr}$ (mean $=66 \mathrm{yr}$ ) and $\mathrm{BMI}$ ranged from 18 to $37 \mathrm{~kg} / \mathrm{m}^{2}$ (mean $\left.=28 \mathrm{~kg} / \mathrm{m}^{2}\right)$.

\section{Rectus Femoris Ultrasound: Nondisabled Subjects}

$\mathrm{B}$ (brightness) mode ultrasonography of the right and left rectus femoris was carried out in 10 nondisabled subjects during a single session by a novice operator (K. H.) and by an experienced operator (J. M.). Five additional volunteers underwent ultrasonography only by the novice operator. The purpose of these experiments was twofold. The first was to determine the validity of ultrasound measurements obtained with the curved-array transducer compared against the measurements obtained with the linear-array transducer in order to assess intertransducer validity. The second purpose was to determine the agreement between ultrasound measurements obtained by a novice operator and an experienced operator in order to assess interoperator agreement or reliability.

Measurements of muscle cross-sectional area were obtained using a $5 \mathrm{~cm}$-wide linear-array transducer $(15 \mathrm{MHz}$, HFL50x, SonoSite; Bothell, Washington) and a $6 \mathrm{~cm}$-wide curved-array transducer (5 MHz, C60x, SonoSite). The transducers were connected to a hand-carried ultrasound unit (M-Turbo, SonoSite). All images were taken after 20 to $30 \mathrm{~min}$ of rest to avoid fluid shifts, which can induce changes in the dimensions of the interstitial and intracellular compartments of the muscle [17].

During image acquisition, transducers were placed on the anterior aspect of the thigh, perpendicular to its long axis at a point that was three-quarters the distance from the anterior superior iliac spine to the superior aspect of the patellar border. This location was the most proximal position in the thigh where the whole cross-sectional image of the rectus femoris lay within the field of view of both transducers in all subjects. During the study, subjects rested on a gurney with a pillow under the head and the legs maintained in passive extension [9]. Distortion of the underlying tissue during imaging was minimized by gently placing the transducers over the thigh using excess contact gel $[9,12]$. To avoid overestimation of muscle dimensions (oblique imaging), operators used visual feedback to obtain the smallest cross-sectional image [9]. In addition, before rectus femoris cross-sectional dimensions were 
measured on the ultrasound image, participants were instructed to perform gentle contraction-relaxation maneuvers to best delineate the fascia of the rectus femoris. The depth of ultrasound scanning was set to where the femur could be recognized for orientation [9]. In addition, to produce the best contrast between tissues, the operators appropriately adjusted image gain and contrast for each probe and subject [16].

Once the operators were satisfied with the position of the probe and the quality of the image, they froze the image of the rectus femoris on the ultrasound monitor. Next, the inner echogenic line of the rectus fascia displayed on the ultrasound monitor was outlined using a movable cursor (Figure 2). The area contained within the outline was automatically calculated by the ultrasound planimetric software. As previously reported by Seymour et al. [9], the cross-sectional area of the quadriceps was the average of three measurements within 10 percent of one other. Of note, an operator was blind to the scans obtained by the second operator.

\section{Rectus Femoris Ultrasound: Subjects with Chronic Obstructive Pulmonary Disease}

B mode ultrasonography of the rectus femoris of the dominant leg was carried out in 17 subjects with COPD during a single session by experienced operator 1 (J. M.) and experienced operator 2 (A. G.). The purpose of this experiment was to determine the agreement between measurements obtained by two experienced operators;

\section{Curved Probe}

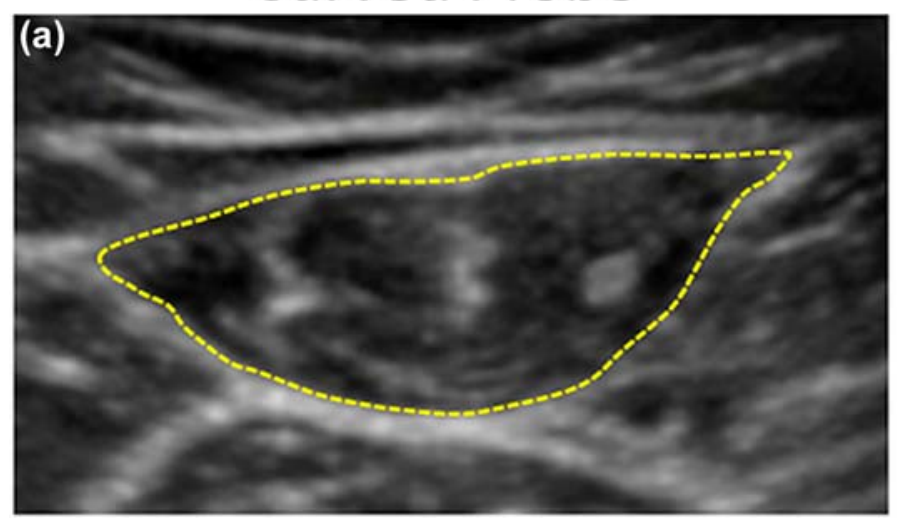

i.e., assessment of interoperator agreement or reliability between experienced operators.

The procedure used in these subjects was similar to that used in the nondisabled volunteers, with two exceptions. First, the $5 \mathrm{~cm}$-wide linear-array transducer could satisfactorily image in its entirety only the cross-sectional image of the distal portion of the quadriceps (see previous section on experiments in nondisabled subjects); therefore, in the subjects with COPD, the two operators used only the $6 \mathrm{~cm}$ wide curved-array transducer (5 MHz, C60x, SonoSite). Second, the muscle was imaged at three-fifths the distance from the anterior superior iliac spine to superior patellar border. This location was the most proximal position in the thigh at which the whole cross-sectional image of the rectus femoris lay within the field of view of the transducer footprint in all subjects.

In a subset of 15 subjects with COPD, interoccasion repeatability of the ultrasound measurements of rectus femoris cross-sectional area (dominant leg) was assessed by the two experienced operators after an interval of $2 \mathrm{~d}$ to 2 wk. During this time interval, subjects continued their normal level of daily activity and experienced no change in their clinical condition, which remained stable.

\section{Quadriceps Strength: Subjects with Chronic Obstructive Pulmonary Disease}

Quadriceps strength was assessed by recording isometric maximum voluntary contractions (MVCs) during knee extension of the dominant leg [9]. The purpose of this experiment was to explore the relationship between

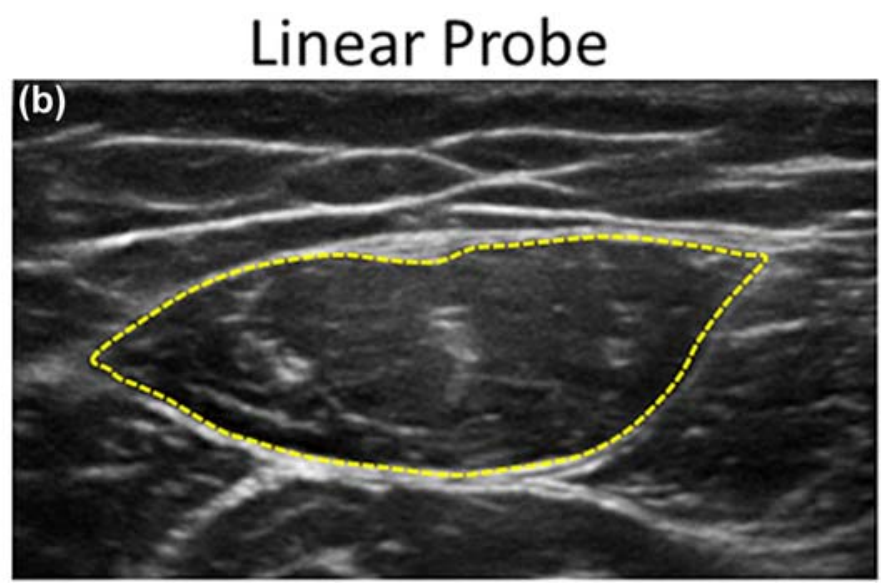

Figure 2.

Image of rectus femoris obtained with (a) curved-array transducer and (b) linear-array transducer. Dotted lines represent manual outline of muscle used in calculation of cross-sectional areas. Both images were obtained with hand-carried ultrasound unit. 
quadriceps strength and rectus femoris measurements obtained with the curved-array transducer in subjects with COPD.

During the MVC maneuvers, subjects rested in the semirecumbent position (hip extension at $150^{\circ}$ ) on a custom-made gurney while keeping the arms folded across the chest and the legs dangling at the gurney's edge (knee angle flexed at $90^{\circ}$ ) [18-19]. The gurney was equipped with a calibrated load cell (Model LCCA-200, Omega; Stamford, Connecticut) connected to a noncompliant strap placed around the subject's dominant leg just proximal to the ankle malleoli [20] and to a strain amplifier/signal conditioner (DMD-465WB, Omega; Stamford, Connecticut). The strain amplifier/signal conditioner, in turn, was connected to a computer for data analysis (DI-158U, DATAQ Instruments; Akron, Ohio). Considering that the rectus femoris is a two-joint muscle that acts on the hip and the knee joints, the subjects' shoulders were securely held against the gurney to avoid the confounding factor of hip movement during MVCs of the quadriceps. In addition, to preclude knee-joint movements, all MVC maneuvers were started at a preload of about $1 \mathrm{~kg}$. This was achieved by controlling the length of the inextensible cable joining the ankle strap and the strain amplifier/signal conditioner. Subjects performed 5-6 isometric contractions each separated by $1 \mathrm{~min}$ of rest until consistent traces within 10 percent of the maximum were obtained [19]. Quadriceps strength was taken as the highest tension recorded during the MVC maneuvers [19].

\section{Statistical Analysis}

The validity of measurements obtained with the curvedarray transducer compared with measurements obtained with the linear-array transducer-the reference-standard technique — was assessed by Bland-Altman analysis [21]. In addition, when the assumption of homoscedasticity (equal variances) [22] was satisfied, validity of measurements was also tested by computing the intraclass correlation coefficient [23]. (Homoscedasticity was calculated by computing the correlation between the difference and the average of the areas obtained with the two transducers [11].)

Bland-Altman analysis [21] and calculation of intraclass correlation coefficients [23] were also carried out to determine interoperator agreement (reliability) and interoccasion repeatability. In addition, typical error of measurements and typical percentage errors [11] were calculated for intertransducer and interoperator measurements. Specifically, typical error of measurement was calculated as the standard deviation of the difference of the areas obtained with the two transducers-or by different operatorsdivided by the square root of two [11]. Typical percentage error was calculated by dividing the mean difference of the areas obtained with the two transducers by the mean area recorded with the curved-array transducer and then multiplying the result by 100 [11]. Finally, the association between intertransducer measurements and the association between interoperator measurements were evaluated by means of Pearson correlation coefficient. Student $t$-test was used to compare the measures obtained with different transducers and different operators. All data are reported as mean \pm SE values. Statistical tests were two-tailed and $p$ values $\leq 0.05$ were considered significant.

\section{RESULTS}

The rectus muscle-fascia boundaries were easily ascertained with each transducer (Figure 2).

\section{Intertransducer Comparisons (Validity)}

Differences in cross-sectional area of rectus femoris recorded with the two transducers were not significant (Table 1). Error of measurements and percentage errors were small. Intertransducer coefficient of determination and intraclass correlation coefficients were high (Table 1). Differences in measurements with the two transducers were distributed around zero (Figure 3).

\section{Table 1.}

Validity of curved-array transducer compared with linear-array transducer.

\begin{tabular}{ll}
\hline \multicolumn{1}{c}{ Measure } & Curved vs Linear* \\
\hline Coefficient of Determination $(p$-value) & $0.96(<0.001)$ \\
Intraclass Correlation Coefficient & 0.982 \\
Bias $^{\dagger}\left(\mathrm{cm}^{2}\right)(p$-value) & $0.05 \pm 0.20(0.83)$ \\
Limits of Agreement $\left(\mathrm{cm}^{2}\right)$ & $-0.35,0.44$ \\
Typical Error of Measurement $\left(\mathrm{cm}^{2}\right)$ & 0.14 \\
Typical Percentage Error & 3.7 \\
Homoscedasticity ( $p$-value) & $-0.08(0.58)$
\end{tabular}

Note: Validity of measurements of cross-sectional area of rectus femoris obtained with curved-array transducer by novice operator and experienced operator in 15 nondisabled subjects and by experienced operator in 10 nondisabled subjects was excellent.

* Images of right and left rectus femoris obtained with linear-array transducer and curved-array transducer placed at three-fourths distance from anterior superior iliac spine to superior patellar border.

${ }^{\dagger}$ Bias was calculated as difference in measurements obtained with two transducers and expressed as mean \pm standard error. 


\section{Interoperator Comparisons (Reliability)}

Differences in cross-sectional area of the rectus recorded by an experienced operator and the novice operator in nondisabled subjects and by two experienced operators in subjects with COPD were not significant (Table 2). Error of measurements and percentage errors were small. Interoperator coefficient of determination for measurements in nondisabled and COPD subjects and intraclass correlation coefficients were high (Table 2). Differences in measurements in nondisabled (Figure 4) and COPD subjects were distributed around zero (Figure 5).

\section{Interoccasion Comparisons (Repeatability)}

Repeatability of measurements recorded by two experienced operators in subjects with COPD were high (Table 3).
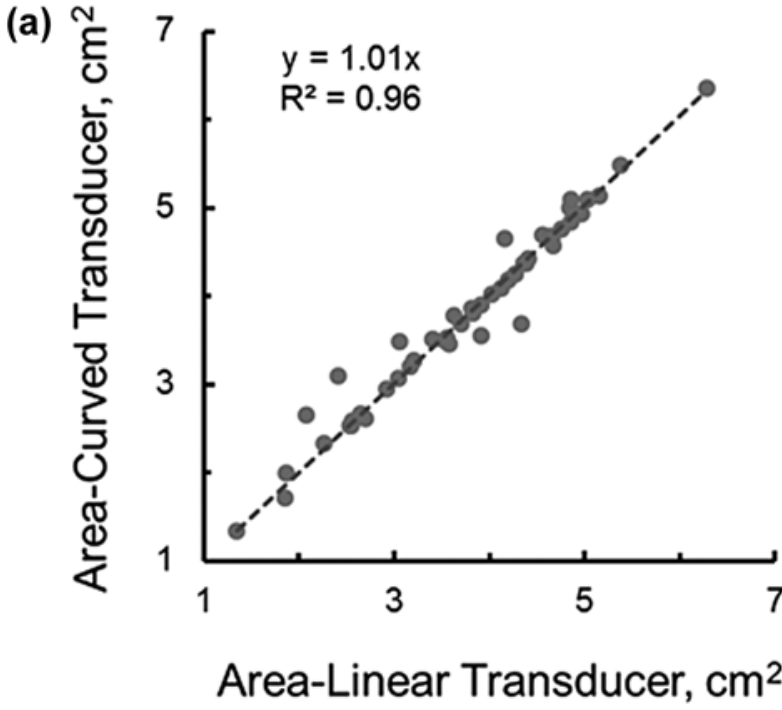

(b)

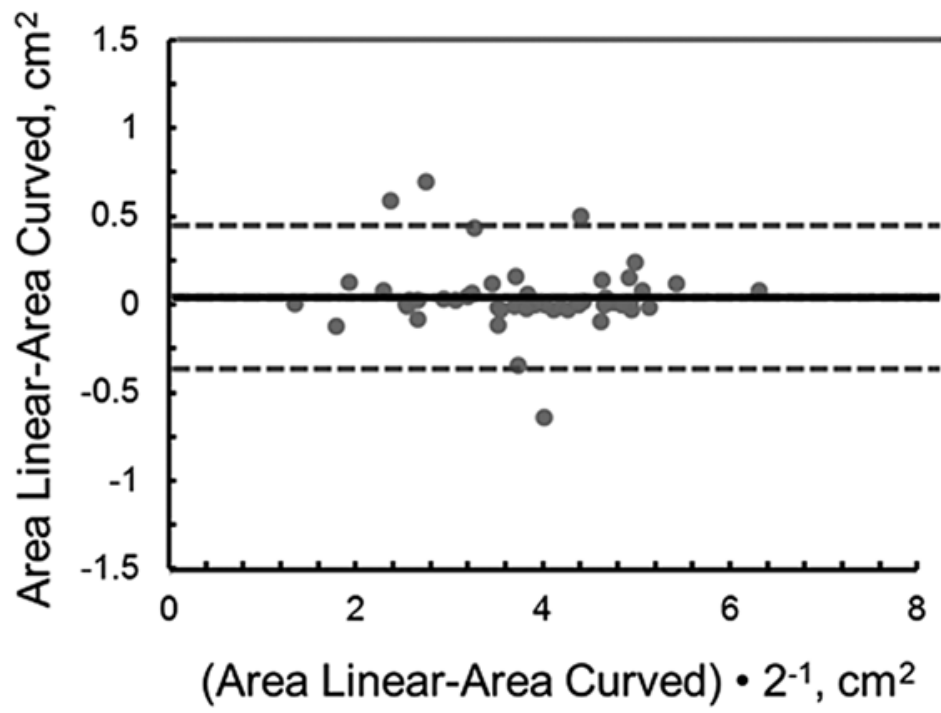

Figure 3.

Intertransducer comparisons (validity). (a) Correlations and (b) Bland-Altman plot of cross-sectional area of right and left rectus femoris obtained with curved-array and linear-array transducer by novice operator in 15 nondisabled subjects and by experienced operator in 10 nondisabled subjects. (a) Rectus femoris cross-sectional area obtained with curved-array transducer was closely related to corresponding measurements obtained with linear-array transducer. (b) Bland-Altman plot of difference between area by curved-array and lineararray transducers versus mean of the two. Bias (solid line) was close to zero and limits of agreement (broken line) were narrow. Only 4 of 50 comparisons of measurements of muscle area were outside respective limits of agreement range (see main text for details).

Table 2.

Reliability of measurements of cross-sectional area of rectus femoris in nondisabled subjects and subjects with chronic obstructive pulmonary disease (COPD).

\begin{tabular}{|c|c|c|}
\hline Measure & $\begin{array}{l}\text { Novice vs Experienced Operator } 1 \\
\text { (Nondisabled) }\end{array}$ & $\begin{array}{c}\text { Experienced Operator } 1 \text { vs Experienced } \\
\text { Operator } 2(\mathrm{COPD})^{\dagger}\end{array}$ \\
\hline Coefficient of Determination ( $p$-value) & $0.70(<0.001)$ & $0.99(<0.001)$ \\
\hline Intraclass Correlation Coefficient & 0.787 & 0.998 \\
\hline $\operatorname{Bias}^{\ddagger}\left(\mathrm{cm}^{2}\right)(p$-value $)$ & $0.35 \pm 0.09(0.12)$ & $0.06 \pm 0.03(0.94)$ \\
\hline Limits of Agreement $\left(\mathrm{cm}^{2}\right)$ & -0.78 to 1.47 & -0.17 to 0.30 \\
\hline Typical Error of Measurement $\left(\mathrm{cm}^{2}\right)$ & 0.40 & 0.08 \\
\hline Typical Percentage Error & 9.7 & 1.4 \\
\hline Homoscedasticity ( $p$-value) & $0.21(0.19)$ & $0.36(0.16)$ \\
\hline \multicolumn{3}{|c|}{$\begin{array}{l}\text { Note: Reliability of measurements of cross-sectional area of rectus femoris obtained by novice operator compared with measurements obtained by experienced } \\
\text { operator in } 10 \text { nondisabled subjects and by two experienced operators in } 17 \text { men with COPD was excellent. } \\
{ }^{*} \text { Images of right and left rectus femoris obtained with transducers placed at three-quarters distance from anterior superior iliac spine to superior patellar border. } \\
{ }^{\dagger} \text { Images of rectus femoris (dominant leg) obtained with curved-array transducer placed at three-fifths distance from anterior superior iliac spine to superior patellar border. } \\
{ }^{\ddagger} \text { Bias was calculated as difference in measurements recorded with two transducers and expressed as mean } \pm \text { standard error. }\end{array}$} \\
\hline
\end{tabular}


(a)

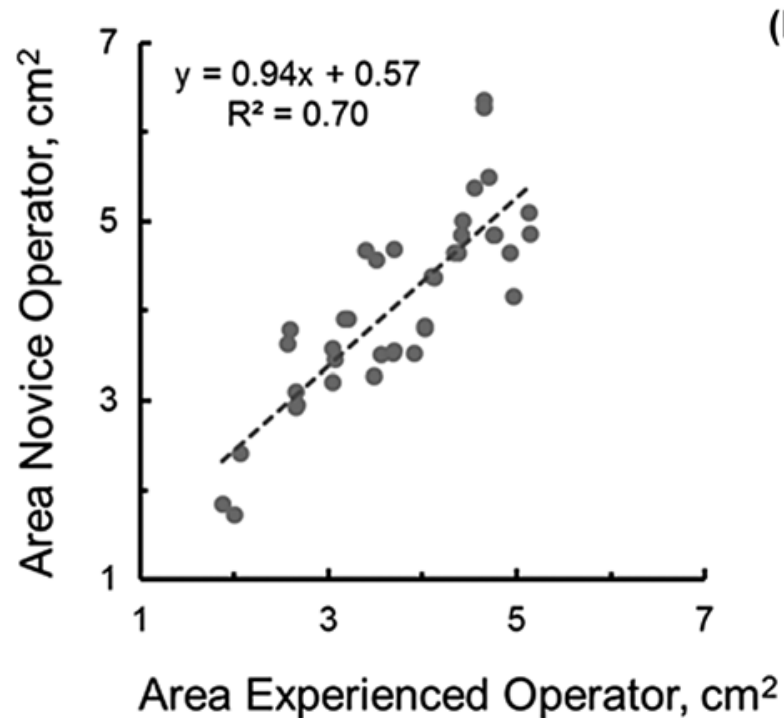

(b)

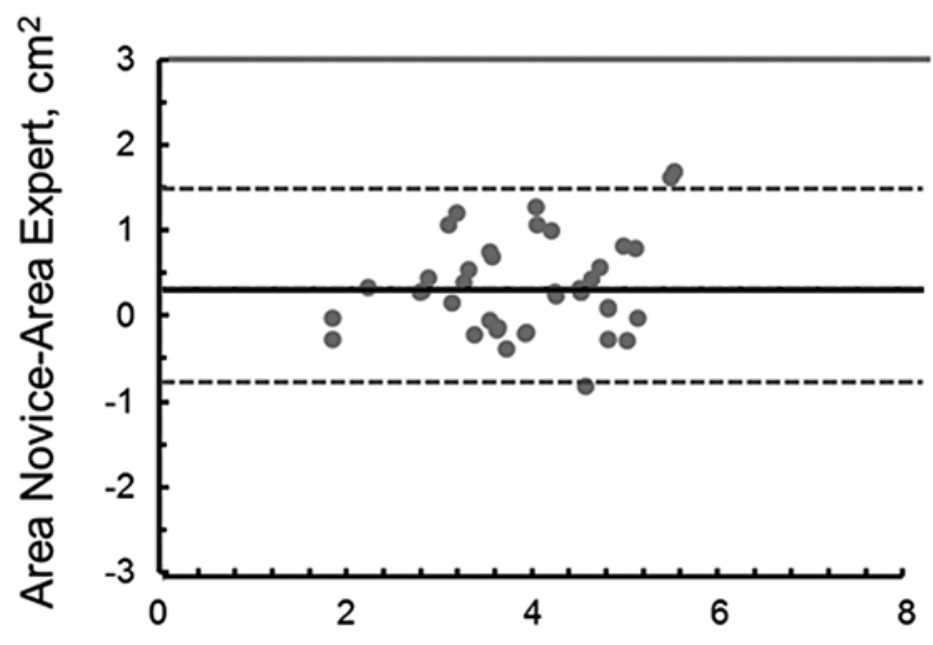

(Area Novice-Area Expert) $\cdot 2^{-1}, \mathrm{~cm}^{2}$

Figure 4.

Interoperator comparisons in nondisabled subjects (reliability). (a) Correlation and (b) Bland-Altman plot of cross-sectional area of right and left rectus femoris obtained with curved-array and linear-array transducer by novice operator and by experienced operator in 10 nondisabled subjects. (a) Rectus femoris cross-sectional area obtained by novice operator was closely related to corresponding measurements obtained by experienced operator. (b) Bland-Altman plot of difference between cross-sectional areas obtained by two operators versus mean of the two. Bias (solid line) was close to zero and limits of agreement (broken line) were narrow. Only 3 of 40 comparisons of muscle area were outside respective limits of agreement range (see main text for details).

\section{Quadriceps Strength and Cross-Sectional Area: Sub- jects with Chronic Obstructive Pulmonary Disease}

The mean \pm SE tension during MVCs of the quadriceps in subjects with COPD was $54 \pm 4 \mathrm{~kg}$. The value of the MVCs of the quadriceps was positively correlated with the dimensions of the muscle recorded by the two experienced operators: coefficient of determination $\left(r^{2}\right)$ of 0.67 and 0.70 for experienced operator 1 (J. M.) and experienced operator 2 (A. G.), respectively ( $p<0.001)$.

\section{DISCUSSION}

This study has four major findings. First, rectus femoris dimensions obtained with a curved-array transducer connected to a hand-carried unit were valid. Second, reliability of measurements by a novice and an experienced operator in nondisabled subjects was high. Third, reliability and repeatability of measurements by two experienced operators in COPD were high. Finally, rectus femoris cross-sectional area recorded with a curved-array transducer was positively related to quadriceps strength in COPD.

\section{Intertransducer Comparisons}

Measurements of the area of rectus femoris with the two transducers were not carried out until the investigators were first satisfied with identification of the muscle fascia on the monitor. This task was easily accomplished by the investigators with each transducer, as signaled by the small within-subject coefficient of variation for lineararray measurements (range $=0.2 \%-6.8 \%$ ) and curvedarray measurements (range $=0.1 \%-6.3 \%$ ).

Rectus measurements obtained with the curved-array transducer were compared to measurements obtained with the linear-array transducer-the reference-standard technique. These comparisons were carried out using several statistical evaluations that uniformly demonstrated the validity of curved-array transducer measurements (Table 1).

\section{Interoperator Comparisons}

Reliability of measurements in nondisabled subjects and in subjects with COPD was high. Nevertheless, typical percentage error of area measurements in nondisabled subjects was seven times greater than the corresponding value in subjects with COPD (Table 2). At least three factors may have contributed to these findings. First, there 
were differences in operator expertise: imaging in nondisabled subjects was obtained by an experienced and a novice operator, whereas it was obtained by two experienced operators in subjects with COPD. Second, measurements of area are very sensitive to operator error. For instance, acquisition and measurement of images obtained by two or more operators can be incongruent as a result of differences in transducer placement (oblique imaging) [9], muscle-contour deformation (caused by dissimilar pressure on the thigh during image acquisition), and errors in tracing the muscle image. Finally, intertransducer comparison required imaging of the rectus at a more distal location in nondisabled subjects than in subjects with COPD, resulting in a smaller cross-sectional image: $4.04 \pm 0.24 \mathrm{~cm}^{2}$ versus $6.03 \pm 0.56 \mathrm{~cm}^{2}(p=0.003)$.

The aforementioned differences in interoperator agreement and repeatability errors are unlikely to be clinically significant. During a period of about $7 \mathrm{~d}$ of critical (a)

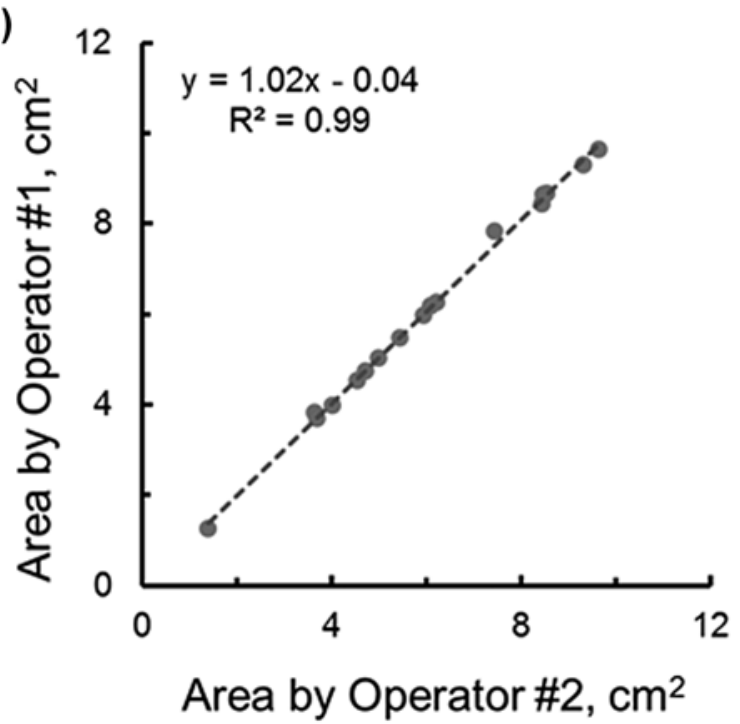

(b)

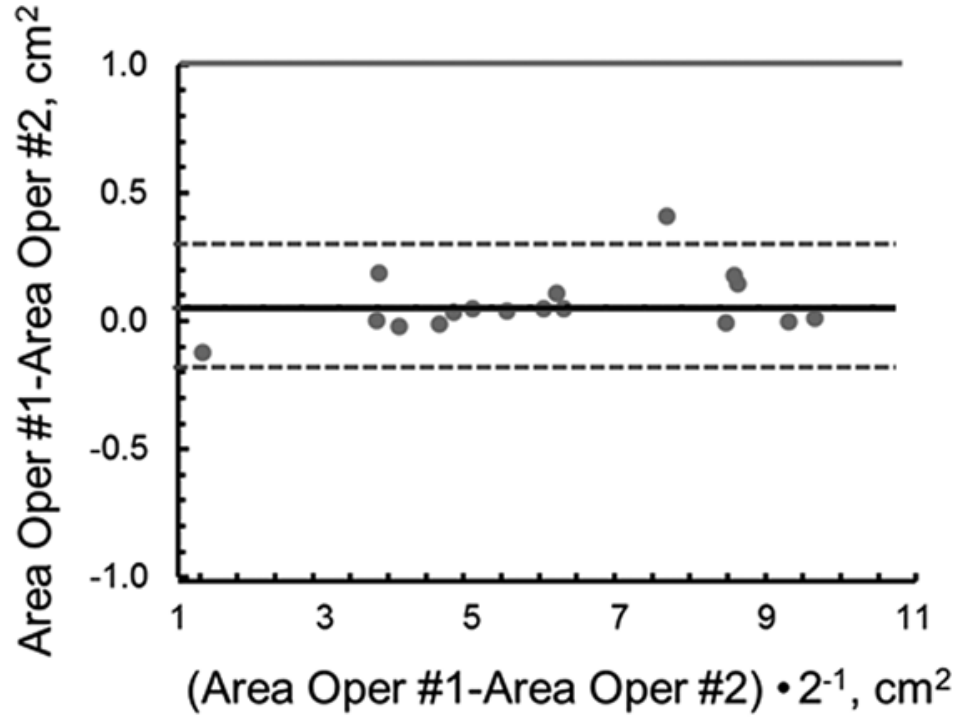

Figure 5.

Interoperator comparisons in subjects with chronic obstructive pulmonary disease (COPD) (reliability). (a) Correlation and (b) BlandAltman plots of cross-sectional area of dominant rectus femoris obtained with curved-array and linear-array transducer by experienced operator 1 and by experienced operator 2 in 17 men with COPD. (a) Rectus femoris cross-sectional areas obtained by two operators were closely related. (b) Bland-Altman plot of difference between cross-sectional areas obtained by two operators versus mean of the two. Bias (solid line) was close to zero and limits of agreement (broken line) were narrow. Only 1 of 17 comparisons of muscle area was outside limits of agreement range (see main text for details). Oper = operator.

Table 3.

Interoccasion repeatability of rectus femoris measurements of cross-sectional area obtained in subjects with chronic obstructive pulmonary disease (COPD) by two experienced operators.

\begin{tabular}{|c|c|c|}
\hline Measure & Experienced Operator 1 (COPD)* & Experienced Operator 2 (COPD)* \\
\hline Coefficient of Determination ( $p$-value) & $0.94(<0.001)$ & $0.88(<0.001)$ \\
\hline $\operatorname{Bias}^{\dagger}\left(\mathrm{cm}^{2}\right)(p$-value $)$ & $0.13 \pm 0.16(0.88)$ & $-0.08 \pm 0.22(0.22)$ \\
\hline Typical Error of Measurement $\left(\mathrm{cm}^{2}\right)$ & 0.43 & 0.59 \\
\hline Typical Percentage Error & 7.6 & 9.8 \\
\hline Homoscedasticity ( $p$-value) & $0.33(0.23)$ & $0.16(0.57)$ \\
\hline
\end{tabular}


illness, decreases in cross-sectional area range from 14 to 18 percent [5,8-9]. Neuromuscular electrical stimulation, for example, can yield a 13 percent increase in quadriceps cross-sectional area [24]. These changes are greater than the typical interoperator percentage error (1.4\%) and interoccasion percentage error (7.6\%-9.8\%) of measurements with the curved-array transducer in this study (Table 3). That is, the curved-array transducer can detect changes expected to occur in response to catabolic or anabolic conditions [5,8-9]. These considerations support the use of curved-array transducers for longitudinal studies of rectus dimensions. Our findings also underscore the ease with which operators can be trained [25] and that curved-array transducers require no greater expertise than that employed in the use of linear-array transducers.

\section{Quadriceps Strength and Rectus Femoris Dimensions: Subjects with Chronic Obstructive Pulmonary Disease}

In subjects with COPD, measurements of rectus crosssectional area recorded with the curved-array transducer were related to quadriceps strength. These results are consistent with a report that rectus cross-sectional area recorded with a wide, linear-array transducer (connected to a console unit) is closely related to quadriceps strength [9]. That is, the close association between quadriceps force and rectus area measured with a curved-array transducer underscores the reliability of this transducer for assessment of muscle abnormalities. In addition, the findings suggest that measurements can be successfully performed with a transducer connected to a hand-carried unit that is less bulky and 3-4 times cheaper than a console-unit.

\section{Critique of Methods}

Most of the nondisabled subjects were not obese, and no subject had lower-limb edema. Obesity and lowerlimb edema will cause the rectus femoris to be located further away from an ultrasound transducer. Linear-array transducers have less tissue penetration than curved-array transducers [26], and thus, an increase in muscle-totransducer distance may impede complete visualization of large muscles such as the rectus femoris. These considerations raise the possibility that our already very positive results with the curved-array transducer would have been even more robust if we had recruited subjects with lower-limb edema or severe obesity (BMI: $35-40 \mathrm{~kg} / \mathrm{m}^{2}$ ).

Echo intensity of the rectus femoris increases with age [27], and thus, identification of the inner margin of the rectus fascia may be less accurate in older individuals. This difficulty might be expected to be greater with the use of curved-array transducers, which, by design, have less image resolution than linear-array transducers [26]. Contrary to this possibility, the operators easily identified the rectus fascia in the 14 subjects with COPD who were older than $70 \mathrm{yr}$.

Operators occasionally reported difficulty in identifying the rectus fascia when using the linear-array transducer. This difficulty was usually caused by the greater image resolution obtained with the linear-array transducer than with the curved-array transducer, because the latter caused excessive accentuation of the connective tissue sheaths that extend from the muscle fascia (epimysium) into the body of the muscle (perimysium). Despite these difficulties, the within-subject coefficients of variation for linear-array and curved-array measurements were equivalent (range: $2.3 \%-3.1 \%$ ) in subjects with an average BMI of 23 and 30, respectively.

\section{CONCLUSIONS}

This is the first demonstration that measurements of the cross-sectional dimensions of the rectus femoris with a curved-array transducer connected to a hand-carried unit are valid, reliable, and reproducible, leading us to contend that this technique is suitable for cross-sectional and longitudinal studies.

\section{ACKNOWLEDGMENTS}

\section{Author Contributions:}

Study concept and design: K. Hammond, E. G. Collins, A. Jubran, M. J. Tobin.

Acquisition of data: K. Hammond, J. Mampilly, A. Goyal, F. A. Laghi.

Analysis and interpretation of data: K. Hammond, F. A. Laghi, E. G. Collins, M. J. Tobin.

Drafting of manuscript: K. Hammond, E. G. Collins, A. Jubran, M. J. Tobin.

Critical revision of manuscript for important intellectual content: M. J. Tobin.

Statistical analysis: F. A. Laghi, E. G. Collins.

Obtained funding: E. G. Collins.

Administrative, technical, or material support: C. McBurney, F. A. Laghi.

Financial Disclosures: The authors have declared that no competing interests exist. 
Funding/Support: This material was based on work supported by a Department of Veterans Affairs, Rehabilitation Research and Development Service grant (F6955R) and Research Career Scientist Award (E. G. Collins, F7338S).

Institutional Review: The study was approved by the local human studies subcommittees and written informed consent was obtained from all participants after full explanation of the aims and procedures. Participant Follow-Up: The authors do not plan to inform participants of the publication of this study.

\section{REFERENCES}

1. Tobin MJ, Laghi F, Jubran A. Ventilatory failure, ventilator support, and ventilator weaning. Compr Physiol. 2012; 2(4):2871-1921. [PMID:23720268]

2. Gruther W, Benesch T, Zorn C, Paternostro-Sluga T, Quittan M, Fialka-Moser V, Spiss C, Kainberger F, Crevenna R. Muscle wasting in intensive care patients: Ultrasound observation of the M. quadriceps femoris muscle layer. J Rehabil Med. 2008;40(3):185-89. [PMID:18292919]

http://dx.doi.org/10.2340/16501977-0139

3. Poulsen JB, Rose MH, Jensen BR, Møller K, Perner A. Biomechanical and nonfunctional assessment of physical capacity in male ICU survivors. Crit Care Med. 2013; 41(1):93-101. [PMID:23222267] http://dx.doi.org/10.1097/CCM.0b013e31826a3f9e

4. Herridge MS, Tansey CM, Matté A, Tomlinson G, DiazGranados N, Cooper A, Guest CB, Mazer CD, Mehta S, Stewart TE, Kudlow P, Cook D, Slutsky AS, Cheung AM; Canadian Critical Care Trials Group. Functional disability 5 years after acute respiratory distress syndrome. $\mathrm{N}$ Engl $\mathrm{J}$ Med. 2011;364(14):1293-1304. [PMID:21470008]

http://dx.doi.org/10.1056/NEJMoa1011802

5. Gerovasili V, Stefanidis K, Vitzilaios K, Karatzanos E, Politis P, Koroneos A, Chatzimichail A, Routsi C, Roussos C, Nanas S. Electrical muscle stimulation preserves the muscle mass of critically ill patients: A randomized study. Crit Care. 2009;13(5):R161. [PMID:19814793] http://dx.doi.org/10.1186/cc8123

6. De Jonghe B, Sharshar T, Lefaucheur JP, Authier FJ, Durand-Zaleski I, Boussarsar M, Cerf C, Renaud E, Mesrati F, Carlet J, Raphaël JC, Outin H, Bastuji-Garin S; Groupe de Réflexion et d'Etude des Neuromyopathies en Réanimation. Paresis acquired in the intensive care unit: A prospective multicenter study. JAMA. 2002;288(22):2859-67. [PMID:12472328] http://dx.doi.org/10.1001/jama.288.22.2859

7. Mathur S, Takai KP, Macintyre DL, Reid D. Estimation of thigh muscle mass with magnetic resonance imaging in older adults and people with chronic obstructive pulmonary disease. Phys Ther. 2008;88(2):219-30. [PMID:18056754] http://dx.doi.org/10.2522/ptj.20070052
8. Poulsen JB, Møller K, Jensen CV, Weisdorf S, Kehlet H, Perner A. Effect of transcutaneous electrical muscle stimulation on muscle volume in patients with septic shock. Crit Care Med. 2011;39(3):456-61. [PMID:21150583] http://dx.doi.org/10.1097/CCM.0b013e318205c7bc

9. Seymour JM, Ward K, Sidhu PS, Puthucheary Z, Steier J, Jolley CJ, Rafferty G, Polkey MI, Moxham J. Ultrasound measurement of rectus femoris cross-sectional area and the relationship with quadriceps strength in COPD. Thorax. 2009;64(5):418-23. [PMID:19158125]

http://dx.doi.org/10.1136/thx.2008.103986

10. Marquis K, Debigaré R, Lacasse Y, LeBlanc P, Jobin J, Carrier G, Maltais F. Midthigh muscle cross-sectional area is a better predictor of mortality than body mass index in patients with chronic obstructive pulmonary disease. Am J Respir Crit Care Med. 2002;166(6):809-13.

[PMID:12231489]

http://dx.doi.org/10.1164/rccm.2107031

11. Thomaes T, Thomis M, Onkelinx S, Coudyzer W, Cornelissen V, Vanhees L. Reliability and validity of the ultrasound technique to measure the rectus femoris muscle diameter in older CAD-patients. BMC Med Imaging. 2012;12:7.

[PMID:22471726]

http://dx.doi.org/10.1186/1471-2342-12-7

12. de Bruin PF, Ueki J, Watson A, Pride NB. Size and strength of the respiratory and quadriceps muscles in patients with chronic asthma. Eur Respir J. 1997;10(1):59-64.

[PMID:9032493]

http://dx.doi.org/10.1183/09031936.97.10010059

13. Reeves ND, Maganaris CN, Narici MV. Ultrasonographic assessment of human skeletal muscle size. Eur J Appl Physiol. 2004;91(1):116-18. [PMID:14639480] http://dx.doi.org/10.1007/s00421-003-0961-9

14. Puthucheary ZA, Rawal J, McPhail M, Connolly B, Ratnayake G, Chan P, Hopkinson NS, Phadke R, Dew T, Sidhu PS, Velloso C, Seymour J, Agley CC, Selby A, Limb M, Edwards LM, Smith K, Rowlerson A, Rennie MJ, Moxham J, Harridge SD, Hart N, Montgomery HE. Acute skeletal muscle wasting in critical illness. JAMA. 2013;310(15): 1591-1600. Erratum in: JAMA. 2014;311(6):625.

[PMID:24108501]

http://dx.doi.org/10.1001/jama.2013.278481

15. Warner MB, Cotton AM, Stokes MJ. Comparison of curvilinear and linear ultrasound imaging probes for measuring cross-sectional area and linear dimensions. J Med Eng Technol. 2008;32(6):498-504. [PMID:19005964] http://dx.doi.org/10.1080/03091900701695533

16. McMeeken JM, Beith ID, Newham DJ, Milligan P, Critchley DJ. The relationship between EMG and change in thickness of transversus abdominis. Clin Biomech (Bristol, Avon). 2004;19(4):337-42. [PMID:15109752] http://dx.doi.org/10.1016/j.clinbiomech.2004.01.007 
17. Berg HE, Tedner B, Tesch PA. Changes in lower limb muscle cross-sectional area and tissue fluid volume after transition from standing to supine. Acta Physiol Scand. 1993; 148(4):379-85. [PMID:8213193] http://dx.doi.org/10.1111/j.1748-1716.1993.tb09573.x

18. Burtin C, Saey D, Saglam M, Langer D, Gosselink R, Janssens W, Decramer M, Maltais F, Troosters T. Effectiveness of exercise training in patients with COPD: The role of muscle fatigue. Eur Respir J. 2012;40(2):338-44.

[PMID:22135284] http://dx.doi.org/10.1183/09031936.00111811

19. Vivodtzev I, Debigaré R, Gagnon P, Mainguy V, Saey D, Dubé A, Paré MÈ, Bélanger M, Maltais F. Functional and muscular effects of neuromuscular electrical stimulation in patients with severe COPD: A randomized clinical trial. Chest. 2012;141(3):716-25. [PMID:22116795] http://dx.doi.org/10.1378/chest.11-0839

20. Amann M, Regan MS, Kobitary M, Eldridge MW, Boutellier U, Pegelow DF, Dempsey JA. Impact of pulmonary system limitations on locomotor muscle fatigue in patients with COPD. Am J Physiol Regul Integr Comp Physiol. 2010;299(1):R314-24. [PMID:20445160] http://dx.doi.org/10.1152/ajpregu.00183.2010

21. Bland JM, Altman DG. Statistical methods for assessing agreement between two methods of clinical measurement. Lancet. 1986;1(8476):307-10. [PMID:2868172] http://dx.doi.org/10.1016/S0140-6736(86)90837-8

22. Norman GR, Streiner DL. Repeated-measures ANOVA. In: Norman GR, Streiner DL, editors. Biostatistics: The bare essentials. Shelton (CT): People’s Medical Publishing House; 2008. p. 107-16.

23. Rankin G, Stokes M. Reliability of assessment tools in rehabilitation: An illustration of appropriate statistical analyses. Clin Rehabil. 1998;12(3):187-99. [PMID:9688034] http://dx.doi.org/10.1191/026921598672178340
24. Carvalho de Abreu DC, Júnior AC, Rondina JM, Cendes F. Muscle hypertrophy in quadriplegics with combined electrical stimulation and body weight support training. Int J Rehabil Res. 2008;31(2):171-75. [PMID:18467933] http://dx.doi.org/10.1097/MRR.0b013e3282fc0fa4

25. Scott JM, Martin DS, Ploutz-Snyder R, Caine T, Matz T, Arzeno NM, Buxton R, Ploutz-Snyder L. Reliability and validity of panoramic ultrasound for muscle quantification. Ultrasound Med Biol. 2012;38(9):1656-61. [PMID:22749820] http://dx.doi.org/10.1016/j.ultrasmedbio.2012.04.018

26. Carmody K, Moore C, Feller-Kopman D. Probe selection, machine controls and equipment. Handbook of critical care and emergency ultrasound. New York (NY): McGraw Hill; 2011.

27. Arts IM, Pillen S, Schelhaas HJ, Overeem S, Zwarts MJ. Normal values for quantitative muscle ultrasonography in adults. Muscle Nerve. 2010;41(1):32-41. [PMID:19722256] http://dx.doi.org/10.1002/mus.21458

Submitted for publication August 26, 2013. Accepted in revised form March 26, 2014.

This article and any supplementary material should be cited as follows:

Hammond K, Mampilly J, Laghi FA, Goyal A, Collins EG, McBurney C, Jubran A, Tobin MJ. Validity and reliability of rectus femoris ultrasound measurements: Comparison of curved-array and linear-array transducers. J Rehabil Res Dev. 2014;51(7):1155-64.

http://dx.doi.org/10.1682/JRRD.2013.08.0187

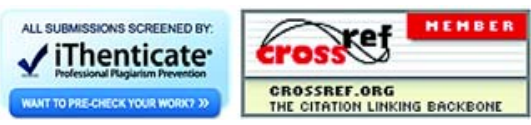

